\title{
Salvage antegrade endoscopic ultrasound-guided pancreatic guidewire placement allowing subsequent double-balloon ERCP
}

During endoscopic retrograde cholangiopancreatography (ERCP), biliary cannulation is still challenging in patients with anatomical variations, such as an intradiverticular ampulla or surgically altered anatomy [1,2]. While the doubleguidewire (DGW) technique is one of the possible rescue techniques [3,4], pancreatic duct (PD) guidewire placement for DGW is sometimes impossible. Endoscopic ultrasound (EUS)-guided biliary access, such as the rendezvous technique, is increasingly used when cannulation has failed but this technique also needs a dilated biliary duct for EUS-guided puncture. We present a successful DGW biliary cannulation using PD guidewire placement under EUS guidance [5] in a patient with failed biliary access by ERCP and EUS ( $\triangleright$ Video 1).

A 74-year-old man with a history of distal gastrectomy and Roux-en-Y reconstruction was admitted with cholangitis due to choledocholithiasis. Double-balloon endoscopy-assisted ERCP (DBE-ERCP) was attempted, but biliary cannulation failed owing to poor visualization of the ampulla. EUS-guided biliary access was then attempted but was unsuccessful because the intrahepatic bile ducts were not at all dilated.

We therefore proceeded to EUS-guided placement of a PD guidewire for subsequent DGW cannulation. Under EUS guidance, a 3-mm PD was punctured using a 19-gauge needle, which was followed by placement of a guidewire through the ampulla into the duodenum ( $\triangleright$ Fig. 1 a). Leaving the guidewire in place, we changed the echoendoscope to a double-balloon endoscope. With the PD guidewire caught through the channel of double-balloon endoscope, the ampulla was facing the endoscope and well visualized ( $>$ Fig. 1 b).

Biliary cannulation was successfully achieved by the DGW technique using a double-lumen cannula with uneven outlets (Uneven Double Lumen Cannula; Pio-

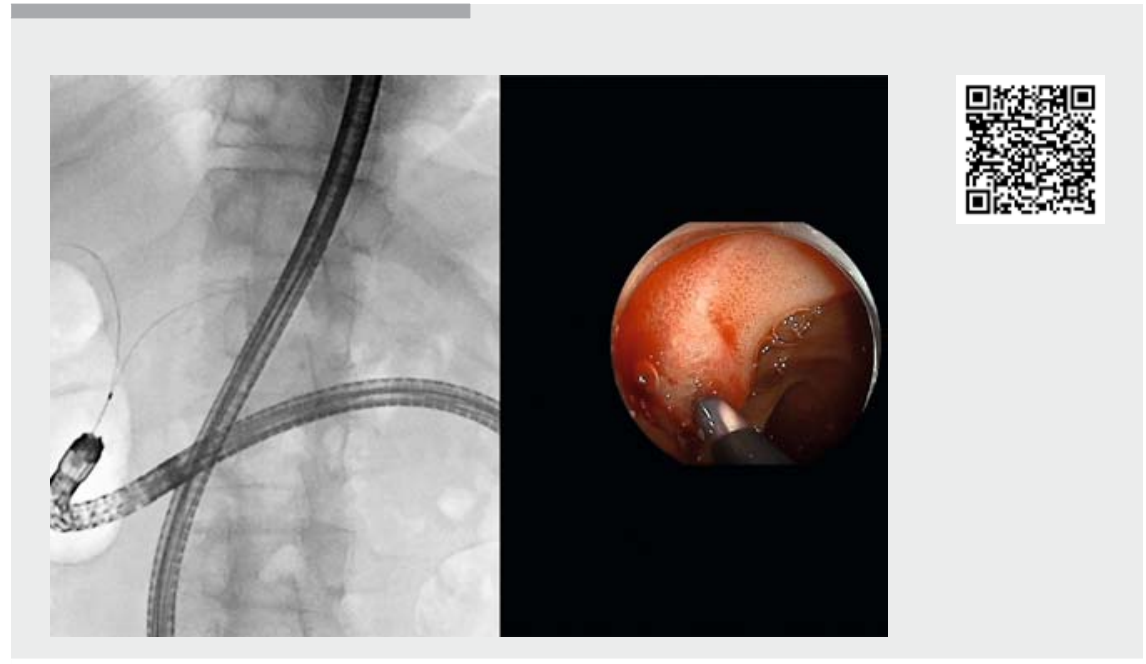

$\checkmark$ Video 1 Endoscopic ultrasound-guided pancreatic guidewire placement for the double-guidewire technique.
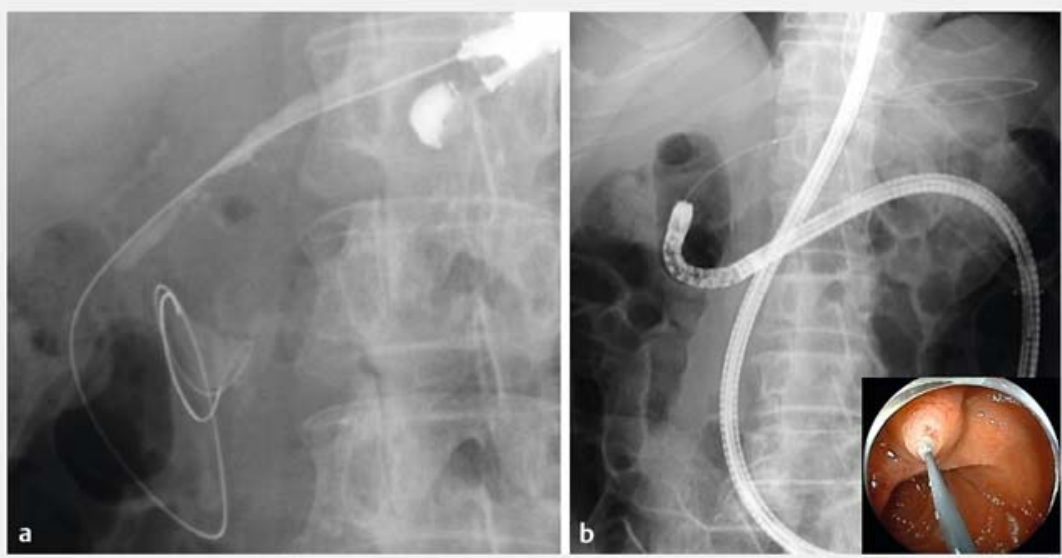

- Fig. 1 Endoscopic ultrasound (EUS)-guided pancreatic guidewire placement for the double-guidewire technique showing: a the pancreatic duct punctured under EUS guidance and a guidewire placed through the ampulla into the duodenum; $\mathbf{b}$ the pancreatic duct guidewire caught through the double-balloon endoscope, making the ampulla well visualized.

lax Medical Devices, Kanagawa, Japan) [4] ( Fig.2a). Subsequently, biliary stones were removed after large-balloon papillary dilation and the procedure was completed ( $\triangleright$ Fig. $\mathbf{2}$ b). A pancreatic drain was not placed, but no pancreatitis or pancreatic fistula was observed.
This case illustrates that EUS-guided PD access can be used for biliary cannulation when ERCP or EUS-guided biliary access has failed.

Endoscopy_UCTN_Code_TTT_1AR_2AK 

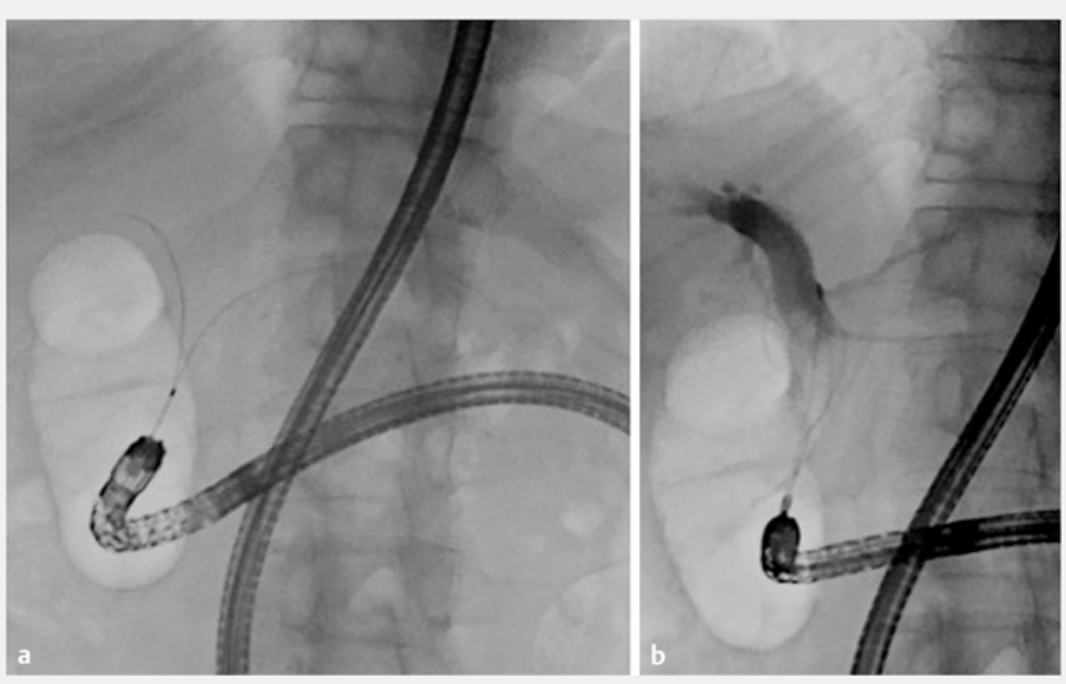

- Fig. 2 Biliary cannulation using the double-guidewire technique showing: a selective biliary cannulation using the double-guidewire technique by inserting a double-lumen cannula over the pancreatic guidewire; $\mathbf{b}$ removal of biliary stones via double-balloon endoscopy-assisted endoscopic retrograde cholangiopancreatography using a basket catheter after large-balloon papillary dilation.

\section{Competing interests}

Dr. Nakai received research grants from Fujifilm and Piolax. The remaining authors declare that they have no conflict of interest.

The authors

Rintaro Fukuda', Tomotaka Saito', Yousuke Nakai $^{1}{ }^{1,2}$, Atsuo Yamada ${ }^{1}$, Hirofumi Kogure ${ }^{1}$, Kazuhiko Koike ${ }^{1}$

1 Department of Gastroenterology, Graduate School of Medicine, The University of Tokyo, Tokyo, Japan

2 Department of Endoscopy and Endoscopic Surgery, Graduate School of Medicine, The University of Tokyo, Tokyo, Japan

\section{Corresponding author}

\section{Yousuke Nakai, MD, PhD}

Department of Endoscopy and Endoscopic Surgery, Graduate School of Medicine, The University of Tokyo, 7-3-1 Hongo, Bunkyo-ku, Tokyo 113-8655, Japan Fax: +81-3-38140021

ynakai-tky@umin.ac.jp

\section{References}

[1] Amer S, Horsley-Silva JL, Menias CO et al. Endoscopic retrograde cholangiopancreatography in patients with surgically altered gastrointestinal anatomy. Abdom Imaging 2015; 40: 2921-2931

[2] Shimatani M, Hatanaka $\mathrm{H}$, Kogure $\mathrm{H}$ et al. Diagnostic and therapeutic endoscopic retrograde cholangiography using a shorttype double-balloon endoscope in patients with altered gastrointestinal anatomy: a multicenter prospective study in Japan. Am J Gastroenterol 2016; 111: 1750-1758

[3] Sasahira N, Kawakami H, Isayama $\mathrm{H}$ et al. Early use of double-guidewire technique to facilitate selective bile duct cannulation: the multicenter randomized controlled EDUCATION trial. Endoscopy 2015; 47: $421-$ 429

[4] Takenaka M, Minaga K, Kamata K et al. Efficacy of a modified double-guidewire technique using an uneven double lumen cannula (uneven method) in patients with surgically altered gastrointestinal anatomy (with video). Surg Endosc 2020; 34: 14321441

[5] Nakai Y, Kogure H, Isayama H et al. Endoscopic ultrasound-guided pancreatic duct drainage. Saudi J Gastroenterol 2019; 25: 210-217
Bibliography

Endoscopy 2021; 53: E320-E321

DOI 10.1055/a-1275-9805

ISSN 0013-726X

published online 23.10 .2020

(c) 2020. Thieme. All rights reserved.

Georg Thieme Verlag KG, Rüdigerstraße 14, 70469 Stuttgart, Germany

\section{ENDOSCOPY E-VIDEOS}

https://eref.thieme.de/e-videos

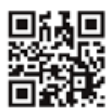

Endoscopy E-Videos is a free access online section, reporting on interesting cases and new techniques in gastroenterological endoscopy. All papers include a high quality video and all contributions are freely accessible online.

This section has its own submission website at https://mc.manuscriptcentral.com/e-videos 